\author{
Cristina Granziera \\ T. Kuntzer \\ F. Vingerhoets \\ C. Cereda
}

\section{Small cortical stroke in the "hand knob" mimics anterior interosseous syndrome}

Received: 6 October 2007

Received in revised form: 2 February 2008

Accepted: 6 March 2008

Published online: 25 September 2008

Sirs: Monoparesis caused by cerebral insult is rare and is usually caused by mass lesions rather than by vascular damage $[1,7]$. At the beginning of the 20th century, J. Lhermitte reported that small cortical strokes could cause weakness restricted to a particular group of fingers ("pseudoperipheral palsy") [6]; recent imaging studies showed that these symptoms are due to motor hand area ("hand knob") lesions $[4,5,9,13]$ and affect predominantly muscles supplied by the "ulnar" or the "radial" nerve [4, 12]. To date, no reports are available about strokes leading to paresis of the muscles exclusively controlled by the median nerve.

We describe a patient with a point-lesion in the right "hand knob", who presented with a predominant deficit of the left thumbindex pinch, a weakness usually

Dr. C. Granziera, MD, PhD ( $\varangle)$

T. Kuntzer, MD · F. Vingerhoets, MD •

C. Cereda, MD

Service de Neurologie

CHUV BH 19

1011 Lausanne, Switzerland

Tel.: +41-21/314-1184

Fax: +41-21/314-1256

E-Mail: Cristina.Granziera@hospvd.ch

This manuscript has not been submitted for publication elsewhere and will not be submitted elsewhere while under consideration for this journal. encountered in the anterior interosseous syndrome.

In January 2007, a 67-year-old female with hypertension and hypercholesterolemia, presented with a sudden onset of an isolated left hand paresis. Detailed examination revealed severe paresis of thumb and index flexion (thumbindex pinch deficit) and light paresis of the flexion of the other fingers and interosseous muscles (M5-). Pronatus quadratus muscle function, tested with a flexed elbow, as well as fingers extensors' were spared. Deep tendon reflexes were symmetric. No other neurological symptoms were observed. Acute perfusion cranial CT scan did not visualize any cerebral lesion. Brain MRI performed after 8 days revealed a hyperintense signal in $\mathrm{T} 2$ and a point-shaped Gadolinium enhancement in $\mathrm{T} 1 \mathrm{WI}$ localized in the "hand-knob" [2,5] (Fig. 1).

Vascular investigations were negative and transthoracic echocardiography showed a moderately patent foramen ovale; procoagulant factors were negative. Electromyography was planned but not per- formed after visualizing the lesion in brain MRI. Clinically, the patient recovered almost completely within 7 days.

This patient presented with an acute hand palsy affecting predominantly two forearm muscles, the flexor pollicis longus and the flexor digitorum profundus of the 2 nd finger, which control the thumbindex pinch movement. These two muscles are supplied by the anterior interosseous nerve (AIN), which is a pure motor branch of the median nerve. Peripheral nerve lesions involving the AIN are associated with brachial neuritis, trauma and extrinsic compression [11]. In our patient, the hypothesis of a vascular central nervous system etiology was supported by the acute instauration of the symptoms, the presence of a very mild diffuse paresis in other muscles of the hand and the presence of multiple cerebrovascular risk factors. A small cortical stroke was confirmed by a brain MRI and an embolic etiology was considered, based on the location of the lesion and on the presence of a patent
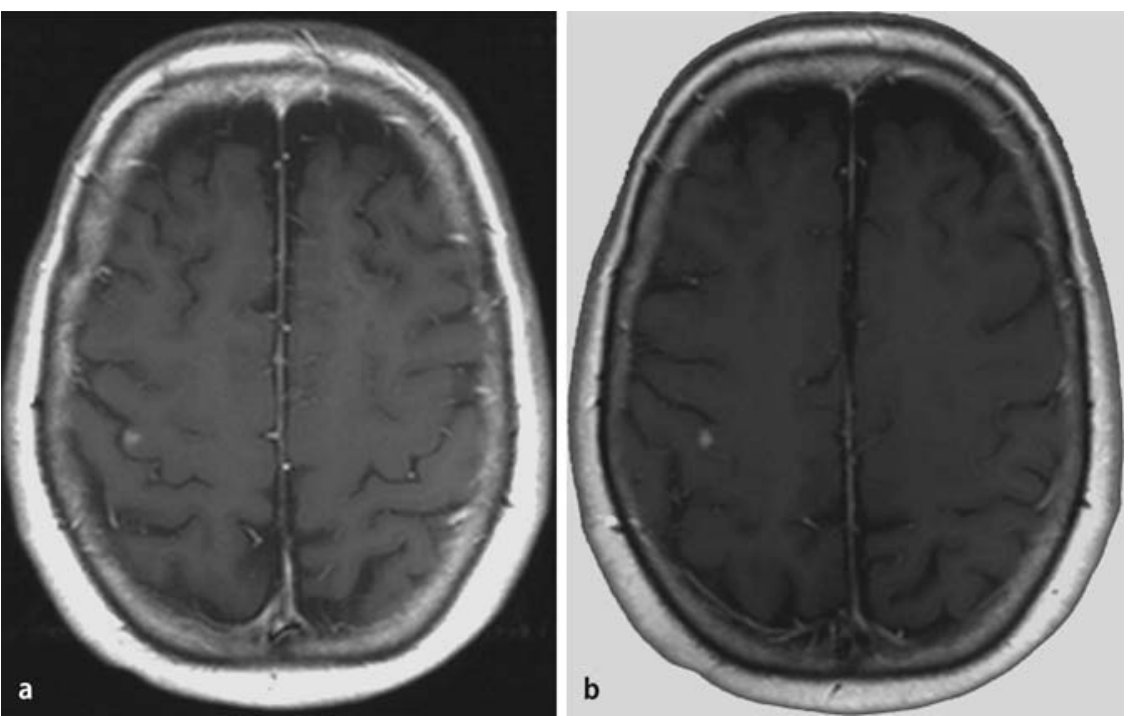

Fig. 1 a MRI, T2WI. Horizontal slice showing a point-shaped hyperintense lesion in the omega-shaped "hand knob" area. b MRI, T1WI (gadolinium): Horizontal slice showing a point-shaped contrast enhancement corresponding to the $\mathrm{T} 2$ hyperintensity 
foramen ovale. The lesion was localized in a region of the handknob, which has been described to control the muscles innervated by the radial nerve $[3,4]$, though the location of ulnar and radial representation shows some degree of flexibility within the knob.

It is actually debated whether the predominance of weakness in a certain muscle group (ulnar, radial, median) is due to lesions of areas controlling selected muscles movements [4] or could be not spatially segregated [10]. This case report supports the theory that the motor representation in the hand area does not follow the classical topography in the human motor hand area. Future fMRI [8], transcranial magnetic stimulation [8] and fiber tracking studies should be performed to better elucidate this point.

Conflict of interest The authors declare no conflict of interest.

\section{References}

1. Ashizawa T, Rolak LA, Hines M (1986) Spastic pure motor monoparesis. Ann Neurol 20:638-641

2. Boroojerdi B, Foltys H, Krings T, Spetzger U, Thron A, Topper R (1999) Localization of the motor hand area using transcranial magnetic stimulation and functional magnetic resonance imaging. Clin Neurophysiol 110:699-704

3. Gass A, Szabo K, Behrens S, Rossmanith C, Hennerici M (2001) A diffusion-weighted MRI study of acute ischemic distal arm paresis. Neurology 57:1589-1594

4. Kim JS (2001) Predominant involvement of a particular group of fingers due to small, cortical infarction. Neurology 56:1677-1682

5. Lee PH, Han SW, Heo JH (1998) Isolated weakness of the fingers in cortical infarction. Neurology 50:823-824

6. Lhermitte (1909) De la valeur sémiologique des troubles de la sensibilité à disposition radiculaire dans les lésions de l'encéphale. Sem Méd 24:277
7. Paciaroni M, Caso V, Milia P, Venti M, Silvestrelli G, Palmerini F, Nardi K, Micheli S, Agnelli G (2005) Isolated monoparesis following stroke. J Neurol Neurosurg Psychiatry 76:805-807

8. Park MC, Goldman MA, Park MJ, Friehs GM (2007) Neuroanatomical localization of the 'precentral knob' with computed tomography imaging. Stereotact Funct Neurosurg 85: 158-161

9. Phan TG, Evans BA, Huston J (2000) Pseudoulnar palsy from a small infarct of the precentral knob. Neurology $54: 2185$

10. Schieber MH (2001) Constraints on somatotopic organization in the primary motor cortex. J Neurophysiol $86: 2125-2143$

11. Stewart J (1987) Focal peripheral neuropathies. New York: Raven

12. Takahashi N, Kawamura M, Araki S (2002) Isolated hand palsy due to cortical infarction: localization of the motor hand area. Neurology 58: 1412-1414

13. Yousry TA, Schmid UD, Alkadhi H, Schmidt D, Peraud A, Buettner A, Winkler P (1997) Localization of the motor hand area to a knob on the precentral gyrus. A new landmark. Brain 120(Pt 1):141-157 